\title{
Confronting Ambiguity: Reading the Intersection of Racial and Sexual Marginalization in Rex vs Singh and Seeking Single White Male
}

\author{
Yilong Liu ${ }^{1}$, Soyang Park ${ }^{2}$ \\ OCAD University, Toronto, Canada
}

\begin{abstract}
This qualitative study of two Canadian films examines how filmmakers and artists explore racial and sexual marginalization and repression in Canada through an in-depth analysis of the films' visual, textual, and sonic elements. Rex vs Singh (Greyson et al., 2008) and Seeking Single White Male (Shraya, 2010), using diverse cinematic devices and self-enacting performances, address different intersecting modes of racial and sexual marginalization against South Asian immigrants in historical and contemporary Canada. Using Louis Althusser's concepts of Repressive State Apparatuses (RSAs) and Ideological State Apparatuses (ISAs) as a key framework, we identify "ambiguity" as a critical space to explore and examine the operation of the state policy (RSAs) in the early $20^{\text {th }}$ century, and workings of the invisible ideology (white normativity) through enlisting their subjects to internalize the norm (ISAs) at present. This discussion is followed by an evaluation of how filmmakers and artists mobilize their "differential consciousness" (Chela Sandoval) to confront these ambiguities as mobile tactics that complement the ongoing race and gender liberation movements. Rather than providing definitive results or solutions, this research aids understanding of the continuing struggles of racialized sexual minorities in Canada-a country that has constitutionalized multiculturalism in 1971 - in light of Canada's $150^{\text {th }}$ celebration (2017).

Keywords: queer, gender and sexuality, film, ethnic studies, ambiguity.
\end{abstract}

\section{Introduction}

The year 2014 marked the $100^{\text {th }}$ year anniversary of Komagata Maru. Carrying 376 passengers to Vancouver, Komagata Maru had departed on May 23, 1914 from Hong Kong. Most of the passengers onboard were Punjabi workers originally from British India. An incident occurred when the passengers on the ship were denied entry by the Canadian immigration department under the Continuous Journey Regulation 1908 and the Immigration Act 1910 that allowed customs officers to turn away any immigrants who did not carry more than 200 dollars at arrival (Johnston, 2016). The Continuous Journey Regulation and the mandated 200 dollars for entering Canada did not apply to any immigrants coming from non-Asiatic regions (i.e. Europe and Americas). Komagata Maru stayed in Victoria harbor, Vancouver for two months and was eventually forced to sail back to India. The denial of Komagata Maru exemplified the government's hope to build Canada into a White nation, excluding non-Europeans and suppressing a further increase of non-White population in the early $20^{\text {th }}$ century. Before the anti-Asian policies set against South Asian immigrants, other non-European groups such as the Chinese and the Japanese were already being affected by the rising anti-Asian sentiment since the late $19^{\text {th }}$ century - due to the racial and economic threat they were perceived to pose to Euro-Canadian residents. ${ }^{3}$ The series of exclusion policy already set and taking an effect then included: An Act to Prevent Chinese from Acquiring Crown Land, legislated in 1884 to restrict Chinese residents in Canada from acquiring properties; ${ }^{4}$ and the Chinese Head Tax (1885-1923), legislated in 1885 to reduce the number of Chinese immigrants entering Canada, under the Chinese Immigration Act (1885). ${ }^{5}$ This having little effect, Canada then banned Chinese immigrants completely in 1923 through the Chinese Exclusion Act (until 1947). Canada also set a limit to the number of Japanese immigrants entering Canada since 1908-first to 400 persons annually and to the further reduced number of 150 in 1928. After Japan became the Allies' enemy during the World War II against the fascist Axis powers, the federal government interned and dispossessed over 20,000 Japanese residents in Canada by establishing Japanese Canadian internment camps in 1942.

As a commemoration of the Komagata Maru incident, an event entitled "In the Wake of the Komagata Maru, Transpacific Migration, Race and Contemporary Art" was organized by Surrey Art Gallery in Vancouver in 2014. Following the exhibition which included paintings, archive images, photographs, and installation works

\footnotetext{
${ }^{1}$ Email: louie.liu@queensu.ca

${ }^{2}$ Email: spark@faculty.ocadu.ca

${ }^{3}$ The Chinese immigration to Canada began in the 1850 s, the Japanese immigration in the 1870 s, and the South Asian immigration in the early 1900s.

${ }^{4}$ It restricted the Chinese from purchasing land from the government, allowing them to purchase it only from other private owners - meaning mostly from other Chinese residents - in pursuit of controlling the housing, the area of residence, and wealth of the Chinese immigrants.

${ }^{5}$ This mandated each Chinese entering Canada to pay $\$ 50$ in tax; the amount was raised to $\$ 100$ and $\$ 500$ gradually.
} 
related to Komagata Maru, the event proceeded with a symposium entitled "Disfiguring Identity: Art, Migration and Exile" wherein five short films were selected for screening: i) Ayesha Hameed's Fire Fences and Flight (2007); ii) Karin Lee's Shattered: The Anti-Asian Riots of 1907 (2007); iii) John Greyson, Richard Fung, and Ali Kazimi's Rex vs Singh (2008); iv) Vivek Shraya's Seeking Single White Male (2010); and v) Divya Mehra's The Importance of Being Earnest (2009). All five films "go against the grain of traditional narratives about migration and exile" (Wong \& Wu, 2014, p. 78). This research paper focuses specifically on the experimental documentary, Rex vs Singh and the performance video, Seeking Single White Male. Through an analysis of these two short films, the paper argues how they confront ambiguities in the intersection of sexual and racial marginalization of South Asian subjects in Canadian society, both the past and the present, concerning external and internalized modes of repression. It seeks to answer the following questions: how does film confront issues of sexual and racial marginalization in historical and contemporary Canada? How does "ambiguity" provide a lens to examine both external and internalized modes of racialized sexual norms?

\section{Methodology and Study Aims}

This qualitative study is based on an analysis of the two films, Rex vs Singh (28 minutes) and Seeking Single White Male (2 minutes and 20 seconds). The study deploys a multidisciplinary mode of inquiry, combining policy and legal studies, race studies, gender and sexuality studies, migration studies, and media studies. The two films reflect the historical, socio-political, and cultural issues and norms that impacted the rights of marginalized South Asian immigrants and stigmatized their sexual being and choice. The overarching theoretical framework of the study follows Louis Althusser's theorization of Repressive State Apparatuses (RSAs) and Ideological State Apparatuses (ISAs) to demonstrate the shifting mechanism of racial and sexual repression of the brown bodies from the historical (RSAs) to contemporary (ISAs) Canada. In addition, we identify "ambiguity" as a key element for understanding racialized sexual repression and how it has only shifted its form from the forceful and external means (such as migration policy, and restriction on owning property which leads to urban segregation) of the early $20^{\text {th }}$ century to a more ideological and internalized mode of repression through White normativity in the contemporary. This research addresses not only the issues of racism but also its perplexing intersection with non-normative sexualities.

\section{Literature Review and Contribution}

Films provide a critical lens into issues of marginalization and repression by visualizing histories that have been seemingly forgotten, neglected, and thus left out of contemporary collective consciousness in multicultural Canada. The significance of rethinking those neglected matters and memories in (colonial) histories has been written on by scholars across various disciplines. English Professor Lisa Lowe (2012) argues that "history becomes 'visible' not in its narrative representation but its defiance of the dominant regimes of representability" (p. 111); Sociologist Avery Gordon (2011) argues those unresolved in histories become haunting matters and social forces that influence the present; Professor Peter Seixas (2006), a specialist in history education and pedagogy, explores how (Canadian) dominant norms have been created based on selective inclusion and exclusion of histories in education curriculums (Seixas \& Ercikan, 2015), thus calling for a more inclusive multicultural education (Ghosh \& Galczynski, 2014); and Wilder, Sanon, Carter, and Lancellot (2017) discussed the issue of lack of diverse narratives still persistent in higher education in the United States even after the Civil rights movement and the multicultural integration policy.

Film also functions as a vital medium for artists to increase the visibility of marginalized subjects and the un-concluded matters by bringing them into the public realm-beyond classroom curriculum that has canonized history education to shape a particular national identity/imagery. Filmmaking has become a powerful practice for marginalized groups (Alías, 2008; Kusumastuti, 2019; Munoz, 1999) to recount un-concluded, forgotten, repressed, and marginalized histories and memories for deconstructing and reconstructing the public perception on the repressed, marginalized, and non-normative subjects. Through the intervention using sonic, visual, and textual elements of film, the filmmakers of Rex vs Singh reconstruct historical narratives of racialized sexual marginalization, whilst transgender artist Vivek Shraya highlights the underrepresented issues of racism within the queer communities in Canada (Teunis, 2007). The psychological consequences of the continuing discrimination against racialized subjects of non-normative sexualities have been written on extensively (Sutter \& Perrin, 2016). Specifically, White normativity (Logie \& Rwigema, 2014; Ward, 2008) continues to assert its dominance across LGBTQ communities in multicultural Canada (Furman, Singh, Darko \& Wilson, 2018).

Current scholarship has provided a vital contribution to discussing issues of multiculturalism, specifically pertaining to racial repression (Byker \& Marquardt, 2016; Calderon Berumen, 2019). Studies on how films confront these problems - in the intersection of racism and sexual ideologies - are however limited. Although film scholar Scott MacKenzie (2013) has given an insightful analysis of Rex vs Singh, Shraya's 
Seeking Single White Male has yet to be studied through an in-depth critical analysis. Moreover, scholarly work on the ways in which how racial prejudice intersects one's sexual desirability is extremely scarce, not to mention the scarcity of academic analysis on how modes of racialized sexual repression and marginalization have shifted from forceful/external means to ideological means/internalized modes. Although the intersection of patriarchy and White normativity has been explored (Etchells, Deuermeyer, Liles, Meister, Suarez \& Chalken, 2017; Kenna \& Russell, 2018 ), this study is the first to provide an academic analysis on Seeking Single White Male, and one of the few to explicitly focus on the intertwining of White normativity and sexual ideologies through a qualitative examination of films.

\section{Film Discussions}

\section{Rex vs Singh - John Greyson, Richard Fung, and Ali Kazimi}

Rex vs Singh re-creates the legal trial against Dalip Singh and Naina Singh ${ }^{6}$ who were both millworkers living in Vancouver and were arrested in 1915 by Italian-Canadian undercover Detective Joseph Ricci and Detective Donald Sinclair, allegedly for sodomy under the Gross Indecency Law (The Criminal Code, 1892). ${ }^{7}$ The film reconstructs the case of a legal dispute based on the existing court transcripts from the period between 1909 and 1929 when a large number of Sikh men living in Vancouver were detained for the same reason (Keung, 2014 , p. 78; Ingram, 2003). ${ }^{8}$ As a whole, the film portrays the incessant anti-Asian sentiment in Vancouver that justified the controversial exclusionary law enforcement against many South Asian subjects as a backdrop of the arrest of these two Sikh men. It also suggests that the state was perhaps using homophobic sentiments and the Criminal Code noted above deceptively, disguising their other intention, that is, to curb the increasing number of racialized populations and stigmatize their presence in an effort to make Canada a White nation, sanctioned by various exclusion laws in effect at that time. The problematic nature of "Gross Indecency" law in application lies in the vagueness of its definition — referring solely to "acts between two men"—which allowed greater arbitrariness in criminalization and punishment of men suspected of engaging in "immoral" acts. As a broader law to punish homosexual men than sodomy and buggery (which in definition requires an "intercourse" between men to be punishable and thus makes it harder to establish the case), the vagueness of the term "Gross Indecency" - alleged by contemporary historians to be intentional—allowed the actual charge to be often left to the court to decide (James, 2019; Ingram, 2003: Prober, 1970).

This arrest can be understood as a symbolic case of Repressive State Apparatus (RSA) in full operation, a characteristic mode of governance of the state to control its population in the Althusserian term. Althusser (1970/2014) noted RSAs as the ways in which the state controls the masses "massively and predominantly by repression [by violent external/forceful means], which function secondarily by ideology [through IRA]" (p. 244). ${ }^{9}$ RSAs contain "the Government, the Administration, the Army, the Police, the Courts, the Prisons, etc." as the multifaceted organ of its operation (Althusser, 1970/2014, p. 243) to legislate laws, arrest, imprison, punish, and segregate populations. In the case of Rex vs. Singh, the non-white, racialized population, as well as those whom the state has deemed to be engaging in a non-normative sexual behavior became the target of such operation. Notably, before this arrest, already by 1907 the fear of economic and labor competition was rising amongst European immigrants in Vancouver concerning the growing number of Asiatic immigrants, giving rise to the exclusion, criminalization, and imprisonment of this population by the state. The anti-Asian sentiment amongst European Canadians materialized through actively and physically targeting Chinese and Japanese immigrants using violent means. For instance, the Asiatic Exclusion League (AEL) was headed and formed by Mayor Alexander Bethune in 1907, supported by a non-union conservative labor party named "Knights of Labour" in order to curb immigrants coming into the U.S. and Canada from the regions of Asia. In the same year, the group destroyed many properties in Chinatown and Japantown in Vancouver (e.g. grocery stores on Powell street) whilst singing "White Canada Forever" (Greyson et al., 2008). Along with these political campaigns and physical assaults sanctioned by the state, this anti-Asian sentiment led to urban segregation as part of a historical account of circumstances that the film provides, underpinning the controversial arrest of two South Asian men. That is, South Asians were restricted from accessing certain public facilities and were removed from their original residences. Queer urban historian and commentator Gordon Ingram notes about this in the film: "Carrol Street in Vancouver was the original line between the so-called White City behind it and the

\footnotetext{
${ }^{6}$ This paper uses the original Punjabi names, "Dalip" and "Naina," in consistency with the filmmakers" use, rather than "Dalep" and "Nana," a colonial transliteration of these names which appear in the original court scripts of 1915 .

${ }^{7}$ Gross Indecency Law appears in the section 178 of the Criminal Code 1892

https://archive.org/details/criminalcodevic00canagoog/page/n88

${ }^{8}$ Gordon Brent Ingram has noted that there were approximately eight court dossiers of arrests under Gross Indecency, between 1909 and 1921 (Ingram, 2003). Amongst these cases, seven of them involved Sikh men (with the last name Singh).

${ }^{9}$ Ideological State Apparatuses (ISA), as we will discuss more later, function predominantly through ideologies (Althusser, 1970/2014, p. 85 ).
} 
Oriental city on the other side. Those apartheid-like lines shifted every five to ten years and often involved a riot" (Greyson et al., 2008).

Two important legislations to curb the numbers of Asian immigration included the Continuous Journey Regulation in 1908 and the Immigration Act in 1910. The Continuous Journey Regulation decreed that the immigrants must come directly from their place of origin (Johnston, 2016). The Immigration Act declared that Canadian immigration officers could turn back any immigrants who possessed less than 200 dollars upon arrival (as this was a large amount of money at the time). Leading to the arrest in 1915, there had been two important events which deeply agitated Asian communities already residing in Vancouver and also devastated South Asian immigrants sailing in from other territories of British Empire.

The incident of Panama Maru that occurred in 1913 - one year earlier than Komagata Maru—was one of these events, directly affected by these legislations, although with some victory for the wound-be immigrants. The Vancouver immigration department ordered to deport 39 Punjabi passengers (out of 56) who had traveled from Japan on the ship Panama Maru and arrived at the Port of Victoria. The place of departure of these 39 passengers did not meet the Continuous Journey Regulation, and they possessed less than 200 dollars. As the passengers proceeded to petition this order whilst being stranded at the port, in November 1913 a Canadian judge overruled the order determining it to be invalid, finding faults in both policies for not conforming to the Immigration Act. The 39 South Asian passengers thus were permitted to enter. Encouraged by this success, Kamagata Maru began sailing with 376 South Asian immigrants on board, having departed from British Hong Kong and arriving at the Vancouver port in 1994. Despite the previous ruling with regard to Panama Maru, however, the immigration department again denied the entry and ordered to deport all passengers except 24. The protest launched by the passengers to demand entry ensued for two months and was met with a violent confrontation with the officials, police, and the troops at the port (Komagata Maru Continuing the Journey, 2011). Even after this long confrontation and the court appeal by South Asian community in Vancouver, only 20 passengers were admitted to enter while the rest were forced to depart for Asia.

These two cases demonstrate how the immigration policies at that time were applied with great inconsistency and did not preclude atrocities like the Komagata Maru incident. Despite the Immigration Act of 1910 declaring that all immigrants from Asiatic regions ought to be checked for their possessions and must follow the Continuous Journey Regulation, often at the discretion of the immigration officers, both policies were almost exclusively applied to South Asian immigrants. In the meanwhile, the Chinese and Japanese immigrants at the time were subject to other policies such as the Chinese Head Tax under Chinese Immigration Act (1885).

How are the incidents and anti-Asian sentiments described above related to Naina Singh and Dalip Singh's arrest and legal charge of "attempted buggery"? As noted, the final verdict of the 1915 trial is unknown. The film directors thus set out to invest in this un-concludedness and ambiguity with a plausible speculation on the arrest and the circumstances surrounding it-alluding to it being a ploy (or "excuses") (Greyson et al., 2008) through which the government attempted to not only disguise the real intention but also compensate the fundamental flaws in its immigration policies as noted above. The contested testimonies this film rigorously reenacts and the flaws in the accounts of the white Crown Detectives the film successfully evokes prompt the viewers to question the validity of this arrest. Another important cue for scrutiny is Bella Singh, a South Indian mole and intelligence informant for the immigration department (which played a key role in deporting Komagata Maru). According to the court scripts that the film reconstructs, three months before Naina and Dalip were arrested, Naina was witness against Bella in a trial in which Detective Ricci was aiding the authority's efforts in acquitting Bella and threatened Naina to withhold testimony (Greyson et al., 2008).

In fact, unlike the cases of Panama Maru and Komagata Maru (through which the state sought to control the influx of immigrants from Asiatic regions), the large number of Sikh workers who were already residing in Canada could not be deported or expelled (MacKenzie, 2013, p. 160). For the Canadian immigration policies at the time were largely subject to the British colonial regulation which treated both Punjabi workers migrating to Canada and all subjects in Canada as the equal British subjects. Therefore, the Gross Indecency Law that the municipal government used to criminalize the Sikh men based on the suspicion of "solicitation" of homosexual engagements and "sodomy" could have been the only way it could stigmatize their presence. That is, the policing body might have arrested Naina Singh and Dalip Singh as "test cases" to control South Asian subjects residing in Canada through its regulation of sexual indecency (Greyson et al., 2008). The regulation deemed homosexuality as deviant behaviors that could not be tolerated (Fadel, 1994) and criminalized it until $1969 .{ }^{10}$

What Rex vs Singh highlights for us specifically is the context in which South Asian immigrants at that time were often targeted by the Gross Indecency law, and in so doing, it addresses two different modes in which issues of race and sexuality intersect. That is: (a) through the anti-Asian and homophobic operation of RSA and

\footnotetext{
${ }^{10}$ In 1969, Canadian government finally decriminalized the consensual sexual act (including intercourse) between men of age over 21 (for both parties), if it is taking place in private (Prober, 1970). The age of consent was later reduced to 18 in the 1985 revision.
} 
ISA; and (b) through the paradoxical intersection of racial repulsion and sexual fascination at the bodies of the racialized others latent in colonial psychology.

The narrative of Rex vs Singh indeed carefully reconstructs the matter in dispute to probe into the validity of this charge, regarding (a) the racial and sexual oppression in the context of the state or the ruling class conflating the repressive (RSA) and the ideological (ISA) apparatuses. The other argument this film enacts - as a part of its cinematic imagination-regarding the race and sexuality intersection is (b) the paradoxical intersection of repulsion and fascination at the bodies of the racialized other being the key, albeit disguised, structure of colonial desire and racial imagination. The film mocks this psychological paradox, posing questions about the possibility that the police officer (Detective Ricci) himself might have had a sexual curiosity towards the "well-built South Asian men," although disguised in in his homophobic law enforcement duty. Possibility of the white men having a sexual fascination with the bodies of racialized men intersecting with the taught homophobic fear and racism is echoed in the film through the interview of Ingram, speculating the case through "convergence of xenophobia and racism with a kind of homophobia that involves at the same time a sexual fascination for the bodies of these well-built laboring males" (Greyson et al., 2008). In order to make this speculation a plausible scenario, diverse cinematic devises are used by the directors in the reconstruction of the courtroom disputes and also in re-imagination of the unspoken (all to be discussed in detail in the following section).

These imaginary narratives of the film are indeed invested in a well-established area of postcolonial research: the subject of ironic intersection of racial repulsion against and sexual fascination towards a racialized body, the psychological dimension of which Franz Fanon first elaborated on through his seminal book, Black Skin, White Masks (1952). Based on how the Asian immigrant workers (Chinese and South Asian) back then formed "bachelors societies" as the laws at that time restricted them from bringing their wives or children with them, these isolated racialized workers' communities in Canada became the place for added racial (and sexual) imagination, bearing the effect of further otherization through allegation of "buggery." Literary Studies Professor Gabrielle McIntire echoes that during colonization, "not only [had] the white imagination [of the colonized] surcharged black and brown bodies with an excess of uncontrollable sexuality, but such an imagination [had] also rendered this projected Otherness as bordering on homosexuality" (McIntire, 2008, p. 20).

Another disturbing aspect of the colonial-era racial relation this film prompts us to rethink is the double objectification of the racialized subjects in the context of colonial economy, built on discrimination wherein the racially stratified labor and economic structure created a condition for, i.e, the South Asian immigrants continuing physical manual labor in a low-wage work sector. The well-built body resulting from this physically hard and low-waged labor is now objectified and eroticized by white men who are mostly working in the clerical or management sector. This double objectification is problematic, for the dominant White group exploits the labor of the racialized groups as little mobility is allowed. By 1915, there were more than 6,000 South Asian men working in the lumber mills in Vancouver. The Sikh workers from British India came to Vancouver looking for new economic opportunities and the wage advantage in Canada compared to their home country. However, the fact that non-European workers from Asiatic regions (India, Japan, and China) at that time were consistently - and deliberately, as alleged-placed in low-wage and labor-intensive sectors by the predominantly White society poses an uneasy question (Galabuzi, 2001; Lightman \& Gingrich, 2012). This was to perpetuate an unequal economic relation and distribution of wealth among racial groups by the dominant group, as echoed by Professor Grace-Edward Galabuzi (2001) who specializes in the policy and race relations in Canada. He notes: "racialized immigrants were incorporated into the economy in a way that posed the least risk to the character of the nation" (p. 77). The same pattern of labor allocation also applied to the case of Chinese workers. Once finished with their railroad construction work, they were then placed into labor sectors such as "farming, fishing, logging, or sawmill and canning industries" with little chance for mobility (Jackson \& Kobayashi, 1994, p. 37).

\section{Cinematic Device}

By questioning the truth of the arrest, this experimental documentary confronts various ambiguities using four different modes of cinematic construction of the un-concluded court case as a way of revisiting the past as well as re-imagining it. Each of the four cinematic reconstruction modes has its own take on the Rex vs Singh case for a particular cinematic, sensorial, and political effect, and is produced by a different film directorexcept for the opening segment which is their collective production. The opening segment (8 minutes and 30 seconds) is produced in the form of classic Hollywood courtroom drama with a direct reference to Billy Wilder's Witness for the Prosecution (1957) (MacKenzie, 2013, p. 53), a well-known courtroom drama based on Agatha Christie's novel of the same title. The directors reconstruct the 1915 trial with drama actors, using the remaining 
court transcripts kept in the archive of the Supreme Court of British Columbia. Ali Kazimi produces the second segment (9 minutes) in the format of conventional investigative and historical documentary, for instance, opening the segment with the interview with a queer (urban) historian, Gordon Brent Ingram, giving an account of the historical backdrop of Rex vs Singh case in relation to many sodomy trials taking place in 1909-1929, as well as its uneasy connection to the anti-Asian sentiments at that time leading to the events like Komagata Maru. The third segment ( 5 mins and 17 seconds), directed by John Greyson, uses phantasmatic cinematic devices to reconstruct and re-imagine the history beyond what was recorded in the archival materials in order to satirize the colonial justice system and to reconstruct the unmarked vision of the South Asian immigrants criminalized by this system. The last segment ( 5 minutes), directed by Richard Fung, returns to the courtroom and wraps up the film with a particular haunting effect, utilizing B-roll images of the archived court scripts overlaid with the courtroom dialogues from the first segment, now enacted in an empty courtroom.

In detail, the first segment, following the conventions of Hollywood courtroom drama, engages in reconstructing the historical case, especially the conflicting testimonies between the defendants (Naina Singh and Dalip Singh) and their crown attorney Detective Ricci and his friend Pierce in a courtroom. As reconstructed from the court scripts, Detective Ricci claims that Dalip Singh took him to meet Naina Singh who then suggested that he (Naina) pay Ricci and Pierce 75 cents each for sex near a railroad station. Both Naina and Dalip deny making solicitations for sex as Naina was fully aware that Ricci was an undercover police officer. Following Ricci's testimony, Pierce testifies against the defendants by claiming that Dalip indeed asked him: "would you like to fuck?" (Greyson et al., 2008). The Crown Attorney then questions Pierce for the validity of his statement by stating that Dalip "does not speak English." The Attorney continues to ask Pierce: "so he [Dalip] learned English just for this occasion?" leaving Pierce flustered. The conflicting testimonies regarding Dalip's (in)ability to speak English in this scene (and the following revelation regarding Bella Singh) prompt the viewers to question the probability of Pierce's story and the validity of the charge, leading to the second segment which takes on this inquiry through a historical and investigative analysis of data and the context of the arrest.

The third segment is perhaps the most unexpected and intriguing in this film and is unveiled through a scene of humorously constructed fantasy, turning its genre from a conventional historical documentary (nonfiction) to an experimental documentary (integrated with fictional elements). The imaginary scene stems from the last part of the previous segment addressing the un-concluded nature of the case with its final verdict unknown (with no records available). The humorous, phantasmatic, and parodic nature of this segment evolves around the elephant parable and the "pockets" motif as means of re-counting and re-imagining the unmarked history. Used to parody the entire legal proceeding itself, that is, its formality and the figures operating within the ideological state tainted by the notorious exclusionary policy and homophobic laws, the scene begins with the drawing of an elephant in a picture frame, accompanied by a voice-over: "four blind men were presented with an elephant and asked to describe it. One felt the trunk, another the leg, a third the ear, a fourth the tail" (Greyson et al., 2008). Based on the parable of "the blind men and an elephant" familiar in Hindu, Sikh, Buddhist, and Sufi traditions, this is a story about the limits of perception due to partial knowledge: being blind and touching the object in isolation, the men are unable to perceive the truth of the whole - the elephant. Greyson furthers his imagination inspired by this parable by adding scenes assisted by humorous illustrations in which the elephant's parts are also mistaken for different things by these blind men: the nose mistaken for a water cannon, the leg a pillar, the ear a purse, and the tail a whip. The humor from this parodic reconstruction elicits a further engaging effect on the viewers as per the particular political role this segment is perhaps intended to play - for "humor produces affect in a way that the audience cannot passively spectate, forcing the viewer to actively engage with the content" as film scholar Scott MacKenzie notes (2013, p. 158). Construed as a satire of the arrest and the trial proceeding in acquiring the truth, the blind men imply the white authorial figures in the courtroom (Ricci, Pierson, the Crown Attorney, and the Judge). Many of their visions are impaired and partial - tainted by racism and homophobia. The truth (of the arrest and the testimonies) is thus deemed unattainable.

Another fantasy scene is developed and expanded from the Crown Attorney inquiring "what was in the pocket?" to Naina. Naina answers that he had no money. The Attorney again asks Naina: "what did Detective Ricci do?" Naina responds: "he looked into my pocket." Greyson then takes on and uses the pocket as the focal point and metaphor to re-imagine the historical and personal truths of the figures from the juncture of expressions: "to have (or have not)" (economic condition) and "to look" (sexual gaze), anchoring on it the issues of race, disparity of wealth, and sexuality. That is, the plot suddenly turns into an unexpected, imaginary scene when Naina suddenly changes his testimony to the Attorney, saying "[I] got proof... in pocket" while pulling out a small roll of thread (Greyson et al., 2008). "Having" proof is a rhetorical cue to shift the plot, changing the subject of narratives to the accused (two South Asian men). From this point on, the courtroom drama turns into a cinematic music video where the lyrics of popular music Greyson parodies are inserted metonymically, 
echoing the themes of new plot narratives that Naina or Dalip leads and creating a secondary compound of meanings. The imaginary scene also continues with Dalip suddenly appearing with scissors and cutting the pockets of the white authorial figures in the courtroom, and with Naina taking over the judge's gavel and acting as if he is the judge. All these are phantasmatic components emblematic of subversive re-imagination of history, incorporated as a way to re-imagine and reconstruct the unmarked agency and vision of South Asian immigrants whose names only appear in history as criminals.

Accompanied by motifs such as scissors and a roll of thread, the historically marginalized figures are thus reconstructed in this role-reversing action as those who uncover the truth, initiating remedy to the confusion. The aforementioned elephant parable also serves the same intention - to shed light on their unmarked visionsourcing from the narratives of wisdom specific to their culture. Precisely, Dalip's action of cutting the pockets is construed in a symbolic act of uncovering the truth of economic condition and disparity of wealth noted earlier. Naina and Dalip's testimonies that "[Naina] had no money in [his] pocket" in this context are also made to evoke in the viewers the line of inquiry reflecting the continuing structure of economic disparity along the race line in contemporary Canada. From the cut pockets, Naina and Dalip collect coins while another song, Catch a Falling Pocket - a parody of the song Catch a Falling Star and its lyrics by Greyson: "take your weekly wages, put it in your pocket, buy a place in the crowd"-plays in the background.

The "pocket" is also a metaphor from which sexual imagination of Greyson develops regarding the disguised sexuality of Ricci, that is, his disguised homoerotic desire for South Asian men. Greyson's imagination seemingly derives from, or is due to, the proximity of the pocket's location to the erogenous zones: thighs, penis, and buttocks. In addition, the pocket is where the money for sexual solicitation was allegedly contained (based on Ricci's testimony) and what Ricci looked at in the scene of alleged "attempted buggery" (Naina's testimony). This scene of homoerotic imagination designed by Greyson was already foregrounded in the earlier scene when the different parts of the parable's elephant were being juxtaposed with various imagery-for example, leg/pillar with a white man's thigh and tail/whip with a penis-by Greyson. The music being played with the erotic imagery in the background as the white male figures' pockets were being cut is Ballad of the Pocketed Life, a parody of The Ballad of the Easy Life (1954) with lyrics rewritten by Greyson: “... the budging pockets [implying a homoerotic act of touching the body through his pockets] make the easy life" (Greyson et al., 2008). Subsequently playing is Pocket of the State, a parody of Pocket of a Clown (1993) and its lyrics by Greyson: "regimes of power keep men straight, inside the pocket of the state." This precisely is the cinematic juncture wherein the director establishes a connection between the state and the suppressed sexuality. The scene where Ricci's naked body being stripped of clothes with his embarrassed face and is being touched by a mysterious brown hand-perhaps that of Naina's and/or Dalip's - reaching into the front and back "pockets," that is, a channel into the erogenous zones, of Ricci's trousers is the pinnacle of the director's imagination of the juncture of race and sexuality disguised and unmarked in history.

The pocket-cutting scene is wrapped up by the continuing fantasy scene where Naina and Dalip are now sewing back the pockets that they cut off, but on odd body parts of the white authorial figures. The act of sewing is also construed as the expression of agency and initiative by the historically marginalized figures for a re-imagined history. However, the result of this act of sewing back is absurdity: the pockets now hanging on Pierce's rear (like a tail), the bottom half of the attorney's face (like an elephant's nose), Ricci's groin area (looking like an enormously enlarged penis), and on the judge's ears. These now absurd-looking figures embody the elephant parable itself and is perhaps meant to symbolize the absurdity of the legal proceeding and the charge, as well as the impossibility in reconstructing the truth of the trial after such a long passage of time.

Fung's final segment traces the ghost of the un-concluded trial case with his cinematic device, evoking a ghostly presence of those (especially Naina and Dalip) who disappeared in history without having been vindicated. The B-roll images of the typewritten court scripts from 1915 are accompanied by the sound of a typewriter and light music, as well as the courtroom testimonies and conversations recounted in the background in an empty courtroom. The matters - having turned into ghostly matters "in a culture seemingly ruled by technologies of hypervisibility" which leads us "to believe that neither repression nor the return of the repressed [...] occurs with any meaningful result" (Gordon, 2011, p. 16) - help breaking the illusion of hypervisibility of our own time. Sexual and racial marginalization is still a continuing reality in contemporary Canada, though it is a matter so little acknowledged or discussed-which leads us to our next case study of Seeking Single White Male by Vivek Shraya.

\section{Seeking Single White Male (2010)_Vivek Shraya}


Where are you from; You are so exotic; I'm not attracted to brown boys; You are too attractive to be Indian; You must be mixed; You tan too much; What colour is your penis; Is that what you really look like; You looked better before. (Shraya, 2010) ${ }^{11}$

If Rex vs Singh allows us to understand the historical mode of racial and sexual repression of South Asian immigrant men in the early $20^{\text {th }}$ century Canada, we argue that Vivek Shraya's performance video, Seeking Single White Male (SSWM), produced in 2010, confronts the contemporary mode of racial and sexual marginalization through the internalization of racialized norms of seduction and attraction within the queer communities in multicultural Canada. Through an analysis of the visual, textual, and sonic elements of the performance video, and of the discussions contained in "Seeking Single White Male-Two Years Later \& An Open Letter," 12 both of which Shraya published on his (now "her"13) personal website in 2012 for public viewing. The following sections will discuss: how contemporary racial ideologies (i.e. love for whiteness) is aligned with White normativity which is internalized by queer subjects-perhaps as the effect of the contemporary state that continues to build on such normativity. Shraya's performance of transitioning into a white gay man is also discussed in the context of the ambiguities of its meaning and effect, with regard to the question if this performance subverts the dominant racial and sexual norms, or rather reproduces and re-affirms them.

\section{Racism, White-Normativity, and Attraction}

In the form of digital literature integrated with photographic imagery of the self, punctuated by electronic beats, the first half of the performance video shows Shraya's transformation into a White-passing queer man, and the second half presents Shraya's return to a brown queer man of South Asian descent. The nine sequential photographs document Shraya masquerading as a White man, materialized through altering the hair color to blond and wearing blue contact lenses, that is, incorporating symbols of Caucasian racial phenotypes. As the enlarged texts overlap the images of the self, almost tearing out of the frame and overpowering the images, this juxtaposition of each photograph with a comment he (now she) had received in gay bars creates a visual effect that echoes the relationship between those voices (comments) as social imperatives and one's identity in formation. In other words, while this performance re-enacts the process of one's internalization of the social imperatives conveyed through these comments, it demonstrates how such imperatives, here mediated through and comes from potential love interests that Shraya as a South Asian gay male had encountered, commanding Shraya to subject himself (now herself) to whiteness or a de-racialized look in order to be desired. The intensely charged, rhythmic beats that run in the background of the video, accompanying the overlapping texts and images, produce a theatrical yet destabilizing effect, causing tension in the scene which is displaying a controversial transition of a non-White subject to whiteness.

Seeking Single White Male was made prior to Shraya's trans journey into a woman. Shraya began this project years after he (now she) heard comments in Edmonton gay bars when he (now she) first came out at the age of 19. The comments incorporated into this video (as transcribed above) clearly address the existence of racialized conceptions of desirability within the gay community in Ontario, Canada. Shraya's voluntary incorporation of the social imperatives latent in these racializing and sexualizing voices is thus provocative and deemed controversial.

The significance of this video indeed lies in its provocation that opens up a difficult and somewhat tabooed dialogue on whiteness and White normativity within gay communities-in which the issues of race and sexuality are again tightly intertwined. Not long after the video was published through Shraya's personal website and was reposted on Facebook and Tumblr "dozens of times" by the viewers, this video elicited abundant comments from queer and non-queer viewers alike (Shraya, 2012). Shraya compiled some of the comments that particularly "stood out" to him (now her) and published them in the same website with his (now her) own responses to them through "An Open Letter" with a link to the video.

The viewer-responses Shraya included in "An Open Letter" include: "I don't get how not being attracted to certain racial phenotypes is bad [...] It is a physical ideal. We all have one" by an unknown commentator (Shraya, 2012). This comment precisely elucidates the context that prompted Shraya to set out on this performance addressing the familiar norm and the prevalent stigma that racial preference is not racism, echoing the widespread denial of the existence of racism among queers which disables an open conversation

\footnotetext{
${ }^{11}$ These are the texts that appear as part of the performance video in sequence. https://vivekshraya.com/projects/films/seeking-single-whitemale/ Accessed on October 32018

${ }^{12} \mathrm{https} / / / \mathrm{vivekshraya.com/writing/essays/seeking-single-white-male-two-years-later/.} \mathrm{Accessed} \mathrm{October} 32018$.

${ }^{13}$ It is conventional within LGBT communities and in societies supporting the freedom of gender identities and gender expressions other than the binary that the gender pronoun(s) to be used follows the preference of the person who undergoes sexual-transitioning-including he, she, singular they, ze, sie, hir, co, and ey. As for Vivek Shraya, after the sex change announced in 2016, the artist has adopted the pronoun of "she/her."
} 
about this matter within gay communities. The comments Shraya explores and re-enacts in the video are the ones that he (now she) and others received multiple times within their gay community (Shraya 2012): "I'm not attracted to brown boys" and "you tan too much" (Shraya, 2010), elucidating that skin color is deeply intertwined with the discourse of sexual desire. Such statements endorsing sexual attraction for paler skin deems the darkerskinned bodies as undesirable, leading to body shaming on the part of brown gay men. Trivialization of this as solely a matter of preference-“like one's height, one's weight, one's body size and shape, eye color, and so forth" (Shraya, 2012) as, for instance, seen in the viewer responses - has been the norm despite its problematic and undeniable racist undertone.

It is in this context that Shraya published the performance video to confront the norm and denaturalize it - in the context of internalization of White normativity intertwined with one's sexual (un)desirability within the LGBTQ/queer community in Toronto, Canada, one of the most renowned gay capitals in North America. Professor in Human Sexuality Studies Niels Teunis (2007) echoes how racism and White normativity in the gay male communities are underdiscussed and often repressed subjects. For sexual freedom has been the objective of LGBTQ social movements and resistance since the 1970s, in the post-HIV epidemic era, the voices against White normativity within such communities are often seen as what "[would undermine] the [objectives of] sexual freedom that is the foundation of the gay communities" (p. 266). The critical point is that the ideology of sexual freedom itself becomes precisely "what allows white gay men to turn a blind eye toward problems of racism" (Teunis, 2007, p. 266). Writing in the context of San Francisco, another renowned gay capital in North America along with Toronto, Teunis' argument echoes with Shraya's concerns and consciousness underpinning the SSWM project, directly referencing the "naturalisation of racism" (Shraya, 2012) and the invisible social imperatives for assimilation in the queer community in Toronto.

\section{Ideologies and Ideological State Apparatuses}

As a cue to embark on and prompt the question of White normativity in everyday practices of attraction, seduction, love, and sex, Shraya's performance video demonstrates how racial ideologies have been internalized by the (queer) subjects themselves, and thus it merits a deeper reflexivity. Althusser (1970/2014)'s insight into the internalization of ideology as ISA's mode of operation is illuminating. Ideological State Apparatuses (ISA) function predominantly through ideologies (rather than violence) wherein the state and ruling class ensure their control over the population through social institutions like church, school, media, art, and family which transmit and reproduce ideologies by "interpellation" or "hailing" the subjects with them. For "there are no individuals," according to Althusser, but only subjects that "come into being" through internalization of ideologies (1970/2014, p.190). Precisely, we all are "interpellated" by social norms as if being called out by the police on the street: "hey, you there!" to which we are compelled to respond by turning around our body-the example that Althusser uses in his writing - highlighting the relation between subject, the other, and ideology. Instead of being hailed by the police, the racialized subject is hailed by the comment that "I am not attracted to brown boys" in the scene of attraction and seduction in a gay bar wherein the voice of a potential love interest becomes that of the authority — whose imperative one attempts to meet — as a contingent authority that one identifies oneself with.

Another statement included in the performance video that attests to the familiar racialized norm of attraction in queer communities uttered by white gay men (Shraya, 2012) is: "you are too attractive to be Indian" (Shraya, 2010). The underlying message of the statements such as this could be that Indian gay men are not attractive and/or the utterer was not expecting to find an Indian attractive. However, in this particular case, the utterer was also being confused by the interracial feature of Shraya masquerading with both South Asian phenotypes and Caucasian phenotypes. Affirming the existence of racial discourses of desirability in queer communities, such unhindered statements elucidate how the act of reducing a potential love interest to the colour of skin and the racial phenotypes is naturalized. Another racially charged quotidian expression is found in the screen shot of a conversation Shraya's friend (a Canadian gay male of South Asian origin in his early 20s) was having via a phone chat app, included in "An Open Letter" (Shraya 2012). This particular conversation echoes the exact same words Shraya has heard multiple times and reveals how the issues that Rex vs Singh raises on the cases of inclusion/exclusion in the national imaginary of White Canada are still pressing ones. In the conversation, a gay male (A) texts to Shraya's friend (B): "sexy as fuck, bro"; B replies "Thank you, and ditto"; A texts: "Where are you from..."; B replies "I'm from Toronto"; A asks again: "Where are you really from? Very exotic looking. Hot." White normativity and the innate sense of exclusion is reflected in the ways in which Canadian men of South Asian origin still are not considered to be part of the national imaginary of Canada. The comments here reveal that whiteness is still the norm in the hierarchy of desirability, and that the imagination of Canada as a White nation still continues in the $21^{\text {st }}$ century among the members of its gay communities. 


\section{Ambiguity}

The effect of Shraya's self-transitioning performance from a brown gay male to a white gay male —or more specifically, to one looking like an interracial figure with a dash of whiteness - comes with some ambiguities. It preserves ambiguities within, and as such, it elicits (as meant to be) the different interpretations of its meaning and effect. As queer theorist Judith Butler highlights through her theory of gender as a performative process or drag (mimicry) rather than being pre-given and fixed, the result of which (of this mimicry-performance) is always destined to be ambivalent, we argue that Shraya's cross-racial transitioning performance is also destined to produce an unstable result.

Precisely, the imperative for mimicry (or drag) of the given model (the normative) and ambivalence in its result is applicable to both (a) racial identification as well as (b) gender identification as both are in nature a performative process: notably, the imperative for mimicry of whiteness in racial relations -- is of course an unnatural by-product of colonization and colonialism. Precisely, Butler notes in Bodies that Matter (1993) that "the ambivalence of the drag" reveals how this 'being a man' and this 'being a woman' [through mimicry] are unstable affairs (p. 126), for there are constant slippages between the model imitated and the result of mimicry. Given that the process would never produce a perfect replication of the model, the performance which is meant to reproduce and affirm this model also becomes what might alter/subvert it/the norm ("subversive alternation"). Likewise, White normativity - sustained by the normalization of whiteness as the superior, desired, and idealized - works in a similar fashion in that it has to be imitated and looked up to by the subjects in a Whitedominant space. That is, whiteness is idealized, naturalized, and "reconstituted" through constant reaffirmation of the subjects (or "the subjugated" in the Althusserian term) in the society. Mimicry of whiteness is an imperative to all in this racialized space through their active (external) and internal "disavowal" of association with one's own non-Whiteness (p. 171). As discussed, however, it is the space of ambivalence in mimicry itself that is destined to alter, and in so doing, may end up subverting the norm. Shraya's mimicry of the idealized whiteness through the seeming disavowal of his (now her) brownness being imperfect has produced an ambivalent result. In many photos, Shraya has a mix of blonde hair and blue eyes (white racial phenotypes) along with the unchanged brown skin color and facial phenotypes of South Asian descent, which does not allow him (now her) to completely pass as the model he attempts to emulate. This imperfect mimicry of whiteness is construed as the proof of impossibility of exacting whiteness or a failure of perfect reconstitution of whiteness by its subjects. While based on the comments he (now she) included in the performance video it appears on the surface that the resulting alterative (an interracial look) made him (now her) more desirable to potential love interests in the dating scene, the question remains: for at the same time as perfect whiteness beinginadvertently — defied here, his brownness is also being actively defied.

To sum up, addressing the question whether Shraya's performance and mimicry of whiteness, taking place in a so-called White space, reaffirms the dominant racial norms or challenges them, we argue that though ambivalent it might be, this opens up a space for questioning the taboo while denaturalizing the familiar.

\section{Differential Consciousness}

Rex vs Singh recounts what is left out in the current understanding of Canada's past with regard to the intersection of racial repression of South Asian subjects and criminalisation of homosexuality in the early $20^{\text {th }}$ century. Seeking Single White Male confronts the current racialized norms of sexual desirability the discussion of which has been suppressed and marginalized within the queer communities in Canada.

What is distinguished in these creative interventions is their ability to bring in certain "differential consciousness" as an evolving mode of resistance through the embodied and everyday experiences of the filmmakers and artist as a site to question the dominant racial and sexual norms and consciousness. "Differential consciousness" is a term that feminist theorist Chela Sandoval (2000) used in her influential essay, "U.S Third World Feminism: Differential Social Movement I." "Differential consciousness" recognizes the significance of mobile and performative tactics for the subjects who have formed multiple marginalized identities within racialized and gendered spaces, particularly in relation to the hierarchy of priority within the ongoing social and political movements. To address differing aims and agendas, Sandoval notes that the subjects of this differential requires "kinetic and self-conscious mobility of consciousness," identifying their differential (in-resistance) subject positions and "enact[ing] them differentially" (Sandoval, 2000, p. 53). Thus, the tactics of differential consciousness is not exclusionary but is rather complementary to the ongoing modes of social movements "setting them all into a diverse processual relationship" (Sandoval, p.54). It exists as a contingent site in which self-conscious subjects in different positions weave their own ideology between ideologies kinetically — or like a kaleidoscope - depending on the need: a kaleidoscope functions through movements of two or more glasses, generating new imageries with each movement (Sandoval, p.43). 
Rex vs Singh's montage-like structure - consisting of four segments produced by three different film directors individually and together-functions like a kaleidoscope, with multiple reflecting surfaces to intervene into the neglected issues in history to shed new light on them for renewed contemporary consciousness. Each and as a whole, the montage exemplifies three differential subjects, different areas of expertise, and angles into the matters concerned: John Greyson is a white Canadian queer director, writer, artist, curator, and film producer whose work engages with queer politics and activism; Ali Kazimi is a non-queer, South Asian-Canadian artist, writer, and filmmaker whose work engages with race, migration, social justice, archive, and memory; and Richard Fung is a queer East Asian-Canadian artist and writer whose work explores racism, identity politics, colonialism, immigration, and gay pornography. The multiplicity of subjects (of the authors) itself informs a ground for kaleidoscopic optics - through which to allow a truly international, interdisciplinary, and collaborative enactment of "differential consciousness" to operate a powerful means to challenge the dominant ideologies.

Shraya's performance also mobilizes his (now her) "differential consciousness" as a form of mobile agency "to enlist and secure influence," defying the notion of static identities (Sandoval, 2000, p. 57). His (now her) self-enacting performance and dissemination of the outcomes in public outlets presents "mobility of tactics" (Sandoval, p.57) - tactics that allow oneself to move from one ideology to another and deploy them, depending on the need, without being tied to a singular position. For the tactics of conscious subjects need to reflect multiple "lived realities when experiencing overlapping repressions such as racism, misogyny, and homophobia" (Ordóñez, 2018).

\section{Conclusion}

Through our analysis of Rex vs Singh and Seeking Single White Male, we have discussed the ambiguities latent in the mode of application of immigrant policies under the State operation of racial and sexual repression, in the arrest/imprisonment of South Asian subjects in the past, and in the (de)internalization of White normativity in contemporary spaces. Ambiguity, as we argue, is itself a critical space to explore and examine the operation of the State policy and the invisible ideology which enlists their subjects through its naturalization as a norm. Rex vs Singh demonstrates impactful ways in which the film confronts an un-concluded historical event, using versatile and creative methods of questioning and re-imagining. Seeking Single White Male addresses contemporary modes of racism that function predominantly through internalization of White normativity, carried out and translated onto the codes of seduction and attraction. The short video work evokes the neglected and seemingly invisible forms of racial repression through the artist's self-implicated and selfaltering performance of transitioning to whiteness, transgressing the constructed boundaries of racial norms. Juxtaposing the text and Shraya's photographed self reflects how ideologies surrounding racial identities continue to be constructed and internalized by queer men. Yet Shraya's imperfect mimicry of whiteness also contests the stable workings of constructed racial norms in the space of ambivalence of racial identification. Rex vs Singh and Seeking Single White Male thus exemplify creative and impactful modes of inquiry into and resistance against racial and gender normativity in contemporary Canada, confronting the "ambiguity" innate in the case (Rex vs Singh) and the performance (SSWM) mobilizing their "differential consciousness." That is, at various intersections of racial and sexual identification and repression in Canadian society, Rex vs Singh demonstrates the workings of forceful and external modes of repression in the form of RSAs, while Seeking Single White Male provokes discussions surrounding the workings of internalized/ideological mode of repression (ISAs). The accessibility of film and filmmaking that has increased tremendously over the last few decades makes it a powerful means — as we hope this study have demonstrated — for the marginalized subjects and groups to bring silenced histories and discourses as such out into the public for an open discussion.

\section{Implications}

At the intersection of White normativity and hetero-normativity in the context of Canada, this study provokes a renewed critical attention and discussion into the continual struggle for rights, freedom, and equity for marginalized races and genders beyond Canada. Canada is a nation that has been praised for its multiculturalism constitutionalized in 1971, legalization of same-sex sexual activity between consenting adults in 1969, and same-sex marriage in 2005 (the first outside Europe and the fourth in the world), yet the racialized subjects ("visible minority") and racialized sexual minorities in the country continue to face discrimination in various forms. This study is relevant to any societies dealing with the issues of multiculturalism and struggles of their citizens for freedom and equity, regardless of race and gender beyond the constructed binary and normative. Many countries have adopted multiculturalism as their policy-i.e. South America (Brazil, Argentina, Bolivia, Peru...), Asia (Indonesia, Singapore, Malaysia...), Africa (South Africa, Morocco...), Europe (Germany, United Kingdom, Sweden, Netherlands...), and the Caribbean-though variant in cultural, socio- 
political, and historical contexts. Racism in these countries may often be discussed in terms of social and political rights of their citizens, but the discussion of its implication in culture, language, and identity/psychology as the sites of oppression may fall short, presenting an area that requires continual probing and analysis.

\section{Limitations of Research}

This qualitative study of two Canadian film/videos dealing with the intersection of sexual and racial identities and modes of repression in Canada makes only a small contribution to an area of research which requires a more extensive development. Inspired by Gordon Ingram's novel research into the sodomy trial cases in early Canadian history, Rex vs Singh expands our horizons on the struggles of queers of color, living in one of most acclaimed multicultural and liberal nations. Ingram faced various limitations as a researcher since the court records and transcripts on sodomy arrests were limited and almost absent. Yet the illuminating nature of his findings (racially implicated) has inspired these filmmakers to take on the findings to turn into a film and further shed light on the issues marginalized in public consciousness. A further research into this neglected matter from different geographical, cultural, and historical regions would be imperative, both within and outside the context of (White-dominant) Western multicultural metropolis - with a focus on the role of filmmaking and filmmakers in tackling the issues. For instance, how such repression and marginalization is taking place in nonWestern societies (like China, Korea, and Japan) with relatively homogeneous populations in terms of racial and ethnic composition, while the cultural norms that naturalize repression in various ways in these societies are tainted by different sets of religious, social, cultural, and historical traditions and factors from those that have influenced the cultures of Western metropolis - under a strong influence of, for instance, Christianity.

\section{Acknowledgement}

Special Thanks to Maria-Belén Ordoñez

\section{References}

The Criminal Code, 1892, 55-56 Victoria, chap. 29: Together with an act to amend the Canada Temperance Amendment Act, 1888, being chapter 26 of the same session. (1892). S.E. Dawson. Retrieved from archive.org/details/criminalcodevic00canagoog/page/n88.

The Chinese Immigration Act of 1885. Statutes of Canada. An Act of Respecting and Regulating Chinese Immigration into Canada, 1885. Ottawa: SC 48-49 Victoria, Chapter 71.

Alías, M. (2008). When (non) Anglo-Saxon Queers speak in a Queer language: Homogeneous identities or disenfranchized bodies? In Identity Trouble Critical Discourse and Contested Identities (pp. 7794).Basingstoke, UK: Palgrave Macmillan. doi:10.1057/9780230593329

Althusser, L. (2014). On the reproduction of capitalism: Ideology and ideological state apparatuses (Goshgarian, G. M, Trans.). London, UK: Verso Press. (original work published in 1970, Brewster, B, Trans, 1970).

An Act to Prevent Chinese from Acquiring Crown Land, February 18 ${ }^{\text {th }}$, 1884, Session 2, Ch 2. Retrieved fromhttp://learning.royalbcmuseum.bc.ca/pathways/chinesehistoricalwrongs/act_to_prevent_crown/

Butler, J. (1993). Bodies that matter: On the discursive limits of "sex". New York, NY: Routledge Press.

Byker, E , Marquardt, S . (2016). Curricular Connections: Using Critical Cosmopolitanism to Globally Situate Multicultural Education in Teacher Preparation Courses. Journal of Social Studies Education Research, 7 (2), 0-0. Retrieved from http://dergipark.org.tr/jsser/issue/26846/282297

Calderon Berumen, F. (2019). Resisting Assimilation to the Melting Pot:. Journal of Culture and Values in Education, 2(1), 81-95. Retrieved from http://cultureandvalues.org/index.php/JCV/article/view/25

Etchells, M. J., Deuermeyer, E., Lies, V., Meister, S., Suarez, M. I., \& Chalklen, W. L. (2017). White Male Privilege: An intersectional deconstruction. Journal of Ethnic and Cultural Studies,4(2), 13-27.

Furman, E., Singh, A. K., Darko, N. A., \& Wilson, C. L. (2018). Activism, intersectionality, and community psychology: The way in which Black Lives Matter Toronto helps us examine white supremacy in Canada's LGBTQ community. Community Psychology in Global Perspective, 4(2), 34-54. doi:10.1285/i24212113v4i2p34

Fanon, F., Markmann, C. L., \& Gilroy, P. (2017). Black skin, white masks. London: Pluto Press. (originally published in French in 1952).

Fadel, Alec. (1994). Homosexual offenses in Ottawa, 1950 to 1967 : the medicalization of the legal process. Master Thesis, Concordia University, Canada.

Galabuzi, G. (2001). Canada's creeping economic apartheid: The economic segregation and social marginalisation of racialized groups. Toronto: CSJ Foundation for Research and Education. 
Ghosh, R., \& Galczynski, M. (2014). Redefining multicultural education: Inclusion and the right to be different. Toronto, Canada: Canadian Scholars Press.

Gordon, A. (2011). Ghostly matters: Haunting and the sociological imagination. Minneapolis, MN: University of Minnesota Press Print.

Greyson, J., Kazimi, A., \& Fung, R. (Directors). (2008). Rex vs Singh [Motion picture on DVD]. Vancouver, Canada: Vancouver Queer Film Festival.

Ingram, G. B. (2003). Returning to the scene of the crime: Uses of trial dossiers on consensual male homosexuality for urban research, with examples from twentieth century British Columbia. GLQ: $A$ Journal of Lesbian and Gay Studies, 10(1), 77-110. doi:10.1215/10642684-10-1-77

Jackson, P., \& Kobayashi, A. (1994). Japanese Canadians and the Racialization of Labour in the British Columbia Sawmill Industry. BC Studies, (103), 33-58. doi:https://doi.org/10.14288/bcs.v0i103.930.

James, W. Y. (2019). Imprint of Racism: White Adult Males' Transformational Experience from Racial Antipathy to Racial Reconciliation. American Journal of Qualitative Research, 3(1), 93-116. https://doi.org/10.29333/ajqr/5813

Johnston, H. (2016). Komagata Maru. The Canadian Encyclopedia. Retrieved from www.thecanadianencyclopedia.ca/en/article/komagata-maru/

Kenna, J., \& Russell III, W. (2018). The Culture and History of Standards-Based Educational Reform and Social Studies in America. Journal of Culture and Values in Education, 1(1), 26-49. Retrieved from http://cultureandvalues.org/index.php/JCV/article/view/2

Keung, H. (2014)). Maintaining an artistic direction: From representation to professionalization, in In the Wake of Komagata Maru: Transpacific migration, race and contemporary art. Surrey, Canada: Surrey Art Gallery.

Kusumastuti, F. (2019). Polysemy in and of the Science Fiction Film Arrival (2016). Research in Social Sciences and Technology, 4(1), 73-91. Retrieved from http://ressat.org/index.php/ressat/article/view/398

Lightman, N., \& Gingrich, L. G. (2013). The intersecting dynamics of social exclusion: Age, gender, race and immigrant status in Canada's labour market. Canadian Ethnic Studies, 44(3), 121-145.

Canadian Ethnic Studies Association. Retrieved from Project MUSE database. doi:10.1353/ces.2013.0010

Logie, C. H., \& Rwigema, M. (2014). “The normative idea of Queer is a White person": Understanding perceptions of White privilege among Lesbian, Bisexual, and Queer women of color in Toronto, Canada. Journal of Lesbian Studies, 18(2), 174-191. doi:10.1080/10894160.2014.849165

Lowe, L. (2012). Decolonization, Displacement, Disidentification. Immigrant Acts, 97-127. doi:10.1215/9780822379010-005.

Muñoz, J. E. (1999). Disidentifications: Queers of color and the performance of politics. Minneapolis: University of Minnesota Press.

McIntire, G. (2008). Modernism, memory, and desire: T.S. Eliot and Virginia Woolf. Cambridge: Cambridge University Press.

MacKenzie, S. (2013). Longfellow, B. MacKenzine, S, Waugh, T, (Eds.). The perils of pedagogy: The works of John Greyson. Montreal, Canada: McGill-Queens University Press.

Muñoz, J. E (1999). The autoethnographic performance: Reading Richard Fung's Queer Hybridity, In Disidentifications: Queers of colour and the performance of politics (pp. 77-92). Minneapolis, MN: University of Minnesota Press.

Ordóñez, M. B. (2018). Supervisory comments. Toronto, Canada: OCAD University.

Prober, J. (1970). The Criminal Law Amendment Act 1968-69 (CANADA). The British Journal of Criminology, 10(2), 180-183.

Sandoval, C. (2000). Methodology of the oppressed. Minneapolis, MN: University of Minnesota Press.

Seixas, P. (2006). What Is Historical Consciousness? In Sandwell R. (Ed.), To the Past: History Education, Public Memory, and Citizenship in Canada (pp. 11-22). Toronto; Buffalo; London: University of Toronto Press. Retrieved from http://www.jstor.org/stable/10.3138/j.ctt1287rs0.5.

Seixas, P \& Ercikan, K. (2015). New directions in assessing historical thinking. London: Routledge.

Shraya, V. (2010, August 1). Seeking Single White Male [Video file]. Retrieved from https://vivekshraya.com/projects/films/seeking-single-white-male/

Shraya, V. (2012, August 07). Seeking single white male: Two years later \& an open letter. Retrieved from https://vivekshraya.com/essays/seekingsingle-whitemale-two-years-later/

Sutter, M., \& Perrin, P. B. (2016). Discrimination, mental health, and suicidal ideation among LGBTQ people of color. Journal of Counseling Psychology, 63(1), 98-105. doi:10.1037/cou0000126 
Teunis, N. (2007). Sexual objectification and the construction of whiteness in the gay male community. Culture, Health \& Sexuality, 9 (3), 263-275. doi:10.1080/13691050601035597

Ward, J. (2008). White normativity: The cultural dimensions of Whiteness in a racially diverse LGBT organization. Sociological Perspectives, 51(3), 563-586. doi:10.1525/sop.2008.51.3.563.

Wilder, L. K., Sanon, D., Carter, C., \& Lancellot, M. (2017). Narrative ethnographies of diverse faculty in higher education: "Moral" multiculturalism among competing worldviews. Journal of Ethnic and Cultural Studies, 4(2), 1-12.

Wong, P., \& Wu, K (2015). Introduction, in In the Wake of Komagata Maru: Transpacific migration, race and contemporary art, Surrey, Canada: Surrey Art Gallery. 